\title{
Triazoles as a class of multifunctional corrosion inhibitors. Review. Part IV. Magnesium alloys ${ }^{1}$
}

\author{
Yu.I. Kuznetsov \\ A.N. Frumkin Institute of Physical Chemistry and Electrochemistry, Russian Academy \\ of Sciences, Leninsky pr. 31, 119071 Moscow, Russian Federation \\ E-mail: kuznetsov@ips.rssi.ru
}

\begin{abstract}
This article continues the review of studies (2005-2020) on organic corrosion inhibitors (CIs) of the triazole class and their effect on the corrosion-electrochemical behavior of $\mathrm{Mg}$ alloys. In contrast to the protection of $\mathrm{Cu}, \mathrm{Zn}, \mathrm{Fe}, \mathrm{Al}$, their alloys, and steels with 1,2,3-benzotriazole (BTA) and its derivatives, the protection of Mg alloys is poorly studied; therefore, a wider group of triazoles is analyzed here. BTA, as a low-toxic reagent, has been successfully tested for replacing chromates in the electrolyte for AZ31B alloy anodization. An increase in $C_{\mathrm{BTA}}$ to $5 \mathrm{~g} / \mathrm{L}$ increased the stability of the anodic film, which is explained by the participation of BTA in the formation of a thick and compact film on the alloy. Another option for protecting Mg with BTA is demonstrated by loading it into porous particles of a copolymer that are then sprayed onto the surface of the alloy, followed by coating the layer of encapsulated CI with an epoxy resin. The release of BTA from these particles begins with an increase in $\mathrm{pH}$ due to the cathodic reaction and corrosion. Triazoles are capable of inhibiting the corrosion of $\mathrm{Mg}$ alloys by blocking $\mathrm{Cu}$-containing intermetallic compounds, impurities of iron and other metals that are more electropositive than $\mathrm{Mg}$, which initiate local dissolution of the alloys. In a solution with $\mathrm{pH} 10, \mathrm{BTA}^{-}$anions act as a nucleating agent, which promotes the formation of a dense and highly crystalline $\mathrm{Mg}(\mathrm{OH})_{2}$ film with a homogeneous nanostructure, passivating the AMlite alloy. This distinguishes the mechanism of its protection from that for $\mathrm{Cu}$-containing aluminum alloys, which is associated with the formation of poorly soluble $\mathrm{Cu}(\mathrm{I})$-BTA complexes. The passivating ability of 1,2,4-triazole (TA) and BTA in relation to technical $\mathrm{Mg}(\mathrm{Mg} 90)$ is small even in weakly alkaline solutions, but their derivatives (a mixture of substituted TA - IFKhAN92 and 5-chloro-BTA), especially in mixtures with dioctyl phosphate CI are more effective. An increase in the efficiency of passivation can be achieved by adding vinyltrimethoxysilane to the mixed CI, which increases 8-9 fold the time until the appearance of foci of corrosion on $\mathrm{Mg}$ in a heat and moisture chamber and exceeds the efficiency of chromate protection. According to XPS results, the protection of $\mathrm{Mg}$ by these CIs is due to the formation of a thin film on it, consisting of a mixed $\mathrm{Mg}$ oxide-hydroxide with a chemisorbed nearly-monolayer of organic molecules. A new possibility of using triazoles to protect $\mathrm{Mg}$ alloys from atmospheric
\end{abstract}

\footnotetext{
${ }^{1}$ This study was financially supported by the Program of fundamental scientific research of state academies of sciences for 2013-2020, subject "Development of the fundamental scientific concepts of the protective effect of metal corrosion inhibitors in gaseous and condensed media, nanocomposites, paints and conversion coatings" (state registration number AAAA-A18-118121090043-0).
} 
corrosion, which can be achieved by treatment of their surface in vapors of a low-volatile ("chamber") CI at elevated temperatures, is noted. It was first shown for 5-chloro-BTA as an example.

Keywords: metal corrosion, adsorption, magnesium and its alloys, passivation, corrosion inhibitors, 1,2,3-benzotriazole, 1,2,4-triazole and its derivatives, encapsulated inhibitor.

Received: December 18, 2020. Published: January 15, 2021

doi: $\underline{10.17675 / 2305-6894-2021-10-1-2}$

\section{Introduction}

Magnesium, like aluminum, belongs to the group of light metals; therefore, in our age of automotive and aerospace technology, its use in the form of various alloys continues to expand. In terms of abundance in the Earth's crust, magnesium occupies the sixth place among metals, and its alloys are about 1.5 times lighter than aluminum alloys [1]. The advantages of magnesium include its relative safety for the environment and non-toxicity for humans; its alloys are easily machined, including high-speed milling and turning. Due to the low toxicity of magnesium, much attention has been paid in the past 10-15 years to the study of the possibility of using magnesium alloys as biodegradable materials for implants [2, 3]. Magnesium alloys are also considered as promising materials for electrodes in electrochemical power sources [4].

However, the standard electrode potential of magnesium, $E_{\mathrm{Mg}^{2+} / \mathrm{Mg}}^{0}=-2.37 \mathrm{~V}$ (N.H.E.), is much more negative than the corresponding potential of aluminum, which allows corrosion to occur even in the absence of oxygen due to the cathodic reaction of hydrogen evolution. Such a negative potential makes the thermodynamic possibility of its corrosion in many environments very high. At the same time, pure magnesium has a high affinity for oxygen and is quickly covered with a film consisting of an inner layer of $\mathrm{MgO}$ and an outer porous layer of $\mathrm{Mg}(\mathrm{OH})_{2}$ [5]. Although it possesses some protective properties, it is not passivating and is much thicker than, for example, passive films on stainless steels. It is noted that an increase in the purity of magnesium above $99.85 \%$ does not lead to a decrease in the rate of its corrosion, and alloying of this metal should be used to increase its corrosion resistance.

Although the corrosion potential of magnesium, for example in $3.0 \% \mathrm{NaCl}$, is significantly more positive, $E_{\text {cor }}=-1.7 \mathrm{~V}$ [2], its value also determines the high sensitivity to impurities of nobler metals, such as $\mathrm{Fe}, \mathrm{Cu}, \mathrm{Ni}$, etc. Iron, which can be included in magnesium throughout the entire technological chain of its production and use, turns out to be especially hazardous. Iron-rich particles are typical sites of corrosion as they initiate a microgalvanic pair of metals that stimulates the anodic dissolution of magnesium. The presence of permanently active cathodic regions on anodically polarized magnesium, mainly associated with iron-rich particles, was shown [6]. Later [7], it was shown that the microgalvanic bond between the iron-rich particles and the magnesium matrix leads to the formation of a surface film and a decrease in the anodic reaction rate, which increases $E_{\text {cor }}$. 
Depending on the density of iron-rich particles on the magnesium surface, $E_{\text {cor }}$ can reach the potential of protective film breakdown, and localized corrosion begins. The authors believe that magnesium with different iron contents has the same value of the critical potential for initiating corrosion and $E_{\mathrm{cor}}$ is the factor determining the limit of the corrosion resistance of magnesium.

In a humid but clean atmosphere, the corrosion rate of magnesium itself is low due to the formation of a protective layer of its hydroxide that is formed upon slow hydration of magnesium oxide [1]. The corrosion behavior of high-purity magnesium is well studied, and according to [2], its corrosion rate is often considered as a reference with which to compare the corrosion rates of alloys based on this metal. The atmospheric corrosion is usually only superficial, slow, and generally slower than the corrosion of mild steel and some aluminum alloys. Song et al. [8,9] who studied the change in the appearance of magnesium under various simulated atmospheric conditions found that even in the presence of chlorides in relatively dry air, the corrosive activity of the atmosphere weakly affects the surface of this metal. However, if sprayed with water containing chlorides, corrosion damage can become severe. It has long been known that corrosion spots appear on magnesium in a clean humid atmosphere with $\mathrm{RH} \geq 90 \%$, but areas of undamaged surface persist for a very long time. At $\mathrm{RH}<90 \%$, weak corrosion leads to the formation of an almost invisible film of amorphous $\mathrm{Mg}(\mathrm{OH})_{2}$, if the humidity exceeds this level, and crystalline $\mathrm{Mg}(\mathrm{OH})_{2}$ is the main corrosion product. Contamination of the magnesium surface with a dust or "cathodic" particles accelerates corrosion and causes the rapid appearance of grayish corrosion products [8]. Many magnesium alloys kept indoors or outdoors but without salt spray form a gray film that can even protect them from corrosion.

Chinese researchers who studied the corrosion of pure magnesium under thin electrolyte layers [10] found that hydrogen reduction is the predominating cathodic process on it and under a thin electrolyte layer, and that this process slows down a little with a decrease in its thickness. The anodic process is inhibited more strongly, which indicates that oxygen inhibits both reactions. For this reason, the corrosion resistance of pure magnesium under a thin film of deaerated electrolyte decreases, and corrosion begins to be local in nature. They came to the conclusion that under a thin electrolyte layer, in comparison with the solution bulk, the rate of pit nucleation obviously slows down but the probability of pit growth increases.

More recently, it was noted in the review [2] that the inhibition of magnesium corrosion is a relatively new method in comparison with other anticorrosion technologies. Despite its obvious advantages (no need for special equipment, easy application and low price), the use of corrosion inhibitors (CI) to protect magnesium alloys was not popular due to the lack of effective reagents among them. It can be added that chromates, the well-known inorganic CI of metals, including magnesium and its alloys, have been severely limited in recent decades due to toxicity and even prohibited from use. In view of this, interest in organic CI and, in particular, in their mixtures with some inorganic compounds increased in the past decade. 
For example, the corrosion protection in a $50 \%$ water-ethylene glycol solution of GW103 magnesium alloy (wt.\%: $10.32 \mathrm{Gd}, 3.60 \mathrm{Y}$, and $0.59 \mathrm{Zr}$, the rest $\mathrm{Mg}$ ) with mixtures of inorganic $\mathrm{CI}$ (various salts of $\mathrm{H}_{3} \mathrm{PO}_{4}$, polyphosphate, sodium molybdate and tungstate, $\mathrm{KF}, \mathrm{NaNO}_{2}$ ) with some organic $\mathrm{CI}$ was studied [11]. It was found that the majority of the CIs studied did not have high protective efficiency, with the exception of a mixture of sodium phosphate with sodium dodecylbenzenesulfonate (SDBS). This formulation was studied in detail at the optimal ratio of $1: 1$ at room temperature $\left(25^{\circ} \mathrm{C}\right)$ and an elevated temperature $\left(90^{\circ} \mathrm{C}\right)$. It was shown that the corrosion rate of the alloy decreased with addition of the mixed CI more strongly at ambient temperature than at $90^{\circ} \mathrm{C}$, and corrosion could be suppressed at $C_{\text {in }}=1 \mathrm{~g} / \mathrm{L}$.

The authors believe that the synergism in the protection of this alloy is due to the fact that the added phosphate interacts with DBSN and this makes the protective film on the alloy surface more compact. In another work [12], they found a synergism in the protection of GW103 alloy in corrosive water by a formulation of sodium aminopropyl triethoxy silicate and zinc nitrate. In this case, the organic or inorganic CI alone also had a low efficiency in protecting the magnesium alloy from corrosion, but the inhibitory effect increased significantly when they were used together.

A search for an organic CI for magnesium or its alloys was carried out, first of all, from among compounds capable of forming sparingly soluble complexes with magnesium cations. Among them, 8-hydroxyquinoline stands out, which has long been known as a chelating agent well known in analytical chemistry for extraction of $\mathrm{Mg}^{2+}$ chelates [13]. Gao et al. [14] found that 8-hydroxyquinaline itself was not only an effective CI for the AZ91D magnesium alloy in a solution containing $148 \mathrm{mg} / \mathrm{L} \mathrm{Na}_{2} \mathrm{SO}_{4}, 138 \mathrm{mg} / \mathrm{L} \mathrm{NaHCO}{ }_{3}, 165 \mathrm{mg} / \mathrm{L}$ $\mathrm{NaCl}, \mathrm{pH}$ 8.2, but also formed a synergistic formulation with DBSN.

According to [15], other organic compounds that can form chelate complexes with magnesium cations include some porphyrin derivatives, for example, environmentally friendly 5,10,15,20-tetraphenylporphyrin (TPhP). Having studied the effect of TPhP on the electrochemical and corrosion behavior of pure magnesium in a $0.05 \% \mathrm{NaCl}$ solution, the authors came to the conclusion that it was highly efficient in inhibiting magnesium corrosion. Based on an analysis of infrared and ultraviolet (UV) spectra, they argue that the action of $\mathrm{TPhP}$ as a CI is based on its ability to form a hardly soluble film consisting of its chelate complexes with magnesium on the surface of the latter. In the next work, these authors [16] confirmed that, under the same conditions, TPhP similarly inhibited the corrosion of AZ91D magnesium alloy (wt.\%: 8.3-9.7 Al, 0.35-1.0 Zn, 0.35-1.0 Mn, 0.05 Si, $0.004 \mathrm{~Pb}, 0.025$ $\mathrm{Cu}, 0.001 \mathrm{Ni}$ ), as follows from the results of not only UV and fluorescence spectroscopy but also XPS data. They believe that the deposited chelate complex reduces the porosity of the $\mathrm{Mg}(\mathrm{OH})_{2}$ film and thereby slows down the dissolution of the magnesium alloy.

Salts of higher carboxylic acids have been studied most extensively in recent years as CI for magnesium and its alloys. For example, Liu et al. [17] studied the properties of selfassembled monolayers (SAM) formed on the AZ91D alloy from ethanol solutions of sodium 
salts with general formula $\mathrm{C}_{n-1} \mathrm{H}_{2 n+1} \mathrm{COONa}$, where $n=12,16$, or 18 . $^{2}$ The SAM were formed from carboxylate anions on natural magnesium oxide are studied using methods such as attenuated total reflection Fourier transform IR spectroscopy (ATR-FTIR), X-ray photoelectron spectroscopy (XPS), ellipsometry and measurement of the static contact angle of surface wetting with a water drop $\theta_{\mathrm{H}_{2} \mathrm{O}}$. Ellipsometric measurements showed that the angles of inclination of the alkyl chains on the surface of AZ91D alloy decreased from $40.9^{\circ}$ (for $n=12), 33.4^{\circ}(n=16)$, and $27.8^{\circ}(n=18)$, respectively. Based on the results of ATRFTIR analysis, the authors came to the conclusion that alkyl carboxylate SAMs are attached to the alloy surface by monodentate bonding, i.e., through one oxygen of the carboxylate group. Measurements of $\theta_{\mathrm{H}_{2} \mathrm{O}}$ as a function of the exposure of an alloy sample in an ethanol solution of sodium alkyl carboxylate showed that after $\sim 48 \mathrm{~h}$ it increased significantly and reached constant values. They amounted to $115^{\circ}, 122^{\circ}$, and $131^{\circ}$ for surfaces with SAM formed by alkyl carboxylates with $n=12,16$ and 18, respectively, which indicates an increase in hydrophobicity with the maximum water-repellent properties of SAM in the case of stearate. The anticorrosive properties of monolayers of alkyl carboxylates were assessed by electrochemical impedance spectroscopy (EIS) measurements where samples of a magnesium alloy were immersed in a $0.2 \mathrm{M} \mathrm{NaCl}$ solution with $\mathrm{pH}$ 7. It was found that the longer the alkyl chain in the alkyl carboxylate and the assembly time, the better the corrosion protection by the alkyl carboxylate based SAM. In particular, the SAM formed in a solution of sodium stearate are capable of providing a high degree of protection of the alloy up to $Z=98.5 \%$.

Later, F. Zukki et al. [19] studied the effect of sodium salts of alkylcarboxylic acids on the corrosion of magnesium alloy AZ31 in synthetic cooling water and found that the protective effect of the best CIs among them (sodium caprate, laurate, and myristate) was due to the formation of insoluble magnesium carboxylate layers. Since the solubility of sodium salts of higher alkyl carboxylic acids in water decreases, sodium palmitate $(n=16)$ practically does not inhibit the corrosion of the alloy due to its low solubility.

To provide sufficient solubility of sodium salts of higher carboxylic acids (myristic, palmitic and stearic) in an aqueous solution containing $0.2 \mathrm{M} \mathrm{Na}_{2} \mathrm{SO}_{4}$ and $0.1 \mathrm{M} \mathrm{NaCl}$, Dinodi and Shetty [20] performed experiments at elevated temperatures in the $t$ range of 30$50^{\circ} \mathrm{C}$. They showed that these salts were mixed type $\mathrm{CI}$ for the ZE41 alloy studied (in wt.\%: 4.49 Zn, $1.05 \mathrm{Ce}, 0.7 \mathrm{Zr}, 0.48 \mathrm{La}, 0.12 \mathrm{Pr}, 0.02 \mathrm{Mn}, \mathrm{Nd}<0.01,0.006 \mathrm{Fe}, 0.004 \mathrm{Al}$, the rest $\mathrm{Mg}$ ), i.e., slowed down the cathodic and anodic reactions. Sodium stearate was found to be the most efficient. However, as shown in [21, 22], sodium oleate is the best passivator of commercial magnesium (Mg 90). This CI was later studied in more detail in our laboratory not only individually [23-25] but also as part of mixed CIs [24, 26, 27].

\footnotetext{
${ }^{2}$ Back in the 90 s of the past century, it was shown that the protective properties of sodium alkyl carboxylates in relation to magnesium alloy, for example $\mathrm{Mg}-3 \% \mathrm{Zn}-15 \% \mathrm{Al}$ [18], increase with an increase in the number of carbon atoms in their molecules $\left(n_{\mathrm{c}}\right)$ from 7 to 12.
} 
Of the little studied but very promising CIs of magnesium alloys, we should mention alkyl phosphonates and their salts. In an excellent work, German researchers [28] proved that alkylcarboxylic acids $\mathrm{CH}_{3}\left(\mathrm{CH}_{2}\right)_{n} \mathrm{COOH}(n=2 ; 5 ; 9 ; 13 ; 17)$ and alkylphosphonic acids $\mathrm{CH}_{3}\left(\mathrm{CH}_{2}\right)_{n} \mathrm{P}(\mathrm{O})(\mathrm{OH})_{2}$ (with the same $n$ values) are strongly chemisorbed at room temperature on AZ31 magnesium alloy (MA2 alloy in Russian Federation) whose surface is covered with a thin oxide film ${ }^{3}$. Based on the results of FT-IR and XPS studies, the conclusion was made that these acids were deprotonated upon adsorption on the oxidized alloy surface; therefore, their bonds with the alloy are acid-base interactions of the $-\mathrm{C}(\mathrm{O}) \mathrm{O}-$ and $-\mathrm{P}(\mathrm{O}) \mathrm{O}_{2}^{2-}$ functional groups with surface magnesium cations. Since there is no $\mathrm{CO}$ stretching vibration band in the FT-IR spectra, they believe that the bidentate rather than monodentate binding mode is most likely here. In the case of the adsorption of alkylphosphonic acid, the PO valence band was not detected in the FT-IR spectra; therefore, it is reasonable to assume that bidentate and tridentate binding modes are realized here. In the adsorption of these acids on the alloy surface, the van der Waals interaction of aliphatic chains plays an important role in the stabilization of SAM, which also contributes to its ordering. It is noted that a smaller number of $\mathrm{CH}_{2}$ groups in the alkyl is required for the stability of the SAM formed by alkylphosphonates than for the SAM formed by alkyl carboxylates. This conclusion is confirmed by measurements of the contact angle of water wetting of the alloy surface covered with SAM. In this case, the most hydrophobic AZ31 surface was observed for octadecylphosphonic acid; moreover, it had the best stability. This acid significantly reduces the corrosion current density and slows down the growth of the oxide film.

It can be concluded from this brief overview that, two main groups of compounds can be used as CIs to protect magnesium. One of these includes compounds capable of forming complexes or salts that are hardly soluble in water, while the second group consists of longchain alkyl surfactants also comprising an anionic functional group (carboxyl, phosphonic, etc.). As one can easily see, the CIs of the triazole class known for various metals cannot be attributed to any of these groups for magnesium and its alloys. However, as it will be shown below, they can be fairly good CIs in some cases.

\section{Triazoles}

The most famous and accessible $\mathrm{CI}$ for many metals and alloys of this class of organic compounds, 1,2,3-benzotriazole (BTA) [29-35], has certainly attracted attention in the search for an efficient replacement for toxic chromates and fluorides harmful to the environment. In [36], a low toxic silicate-borate electrolyte $\left(\mathrm{LD}_{50}=965 \mathrm{mg} / \mathrm{kg}\right.$ ) additionally containing BTA $(\leq 10 \mathrm{~g} / \mathrm{L})$ was used in the anodization of magnesium alloy AZ31B containing (wt.\%): 2.5-3.5 Al, 0.6-1.4 Zn, 0.2 Mn, $\leq 0.10 \mathrm{Si}, \leq 0.05 \mathrm{Cu}, 0.005 \mathrm{Ni}$.

\footnotetext{
${ }^{3}$ The acids studied were adsorbed from $1 \mathrm{mmol} / \mathrm{L}$ solutions in anhydrous ethanol.
} 
This process was carried out at room temperature and a constant current density of $i=1.5 \mathrm{~A} / \mathrm{dm}^{2}$.

At the first stage $(<90 \mathrm{~s})$, for samples treated in a solution with or without BTA, sparks do not arise, but gas bubbles appear on the alloy surface. The cell voltage increases linearly with the anodization time and a thin transparent film is formed on it. It increases the surface resistance of the alloy, which quickly raises the cell voltage. When one or two small white sparks appear on the alloy surface, the anodization process passes to the second stage (90$450 \mathrm{~s}$ ). With a further increase in the cell voltage, a large number of white sparks can be detected on the anode surface. A decrease in the slope of "the stress-time" curves indicates a slight increase (compared to the first stage) in the cell voltages, but they increase with an increase in BTA concentration $\left(C_{\mathrm{BTA}}\right)$. At the third stage $(450-600 \mathrm{~s})$, white sparks on the alloy surface are replaced by separate orange ones. With an increase in $C_{\mathrm{BTA}}$ in the electrolyte, the size of orange sparks decreases, and at $C_{\mathrm{BTA}}>7 \mathrm{~g} / \mathrm{L}$, they even disappear. On the other hand, the cell voltage does not change with time during the anodization, indicating that a relatively stable state is established during the anodic film growth.

The effect of BTA on the properties of the oxide film formed by alloy anodization was studied by scanning electron microscopy (SEM), energy dispersive spectrometry (EDS), XPS, X-ray diffraction (XRD), mass loss measurements, potentiodynamic polarization, and electrochemical impedance spectroscopy (EIS). These studies showed that in the process of alloy anodization, the surface morphology, thickness, phase structure, and corrosion resistance of the anodic film strongly depend on $C_{\mathrm{BTA}}$, which the authors explain by the formation of an adsorption layer of BTA on the alloy surface. At $C_{\mathrm{BTA}}=5 \mathrm{~g} / \mathrm{L}$, a compact and thick anodic film is formed, which is able to provide excellent corrosion resistance of AZ31B magnesium alloy.

Ostanina et al. [37] studied the effect of sodium ethylenediaminetetraacetate (EDTA) and BTA on the anodic dissolution of AZ31B alloy. It was shown that in aqueous solutions of sodium sulfate with $C_{\mathrm{Na}_{2} \mathrm{SO}_{4}}$ from 5 to $12.5 \mathrm{mmol} / \mathrm{L}$ or sodium chloride $C_{\mathrm{NaCl}}$ from 2.5 to $30 \mathrm{mmol} / \mathrm{L}$, addition of EDTA and BTA slows down the alloy dissolution. The authors drew attention to the fact that in the presence of these CIs, the dissolution of magnesium not only becomes homogeneous but also decreases the hydrogenation of the surface and the intensity of electrode crumbling accompanied by the passage of its small particles into solution. It was found that the plots of the effect of inhibition of electrochemical corrosion of the alloy by BTA and EDTA on $C_{\text {in }}$ pass through a maximum, and their effect on corrosion losses due to crumbling changes monotonically with an increase in $C_{\text {in }}$.

Chinese researchers [38] studied the possibility of using BTA for loading it into porous particles of a copolymer of lactic and glycolic acid (CPLGA) to create a self-healing system on the surface of AMlite magnesium alloy (in wt.\%: $12.1 \mathrm{Zn} ; 3.5 \mathrm{Al} ; 0.3 \mathrm{Mn} ; 0.1 \mathrm{Ca} ; 0.0029$ $\mathrm{Fe})$. They achieved such a system by directly electrospraying the alloy and then spraying an epoxy onto this inhibited layer. It was found that CPLGA particles quickly react to the onset of alloy corrosion when water appears or the $\mathrm{pH}$ of the medium rises due to the cathodic 
reaction. As a result, the release of BTA immediately begins and continues in time, which leads to the restoration of the coating's protective functions and slows down further corrosion. The kinetics of BTA release from copolymer particles was demonstrated in a borate-alkaline buffer solution $(\mathrm{pH} \mathrm{10)}$ prepared in deionized water by determining the change in $C_{\mathrm{BTA}}$ over time using UV spectrophotometric analysis.

The coatings containing microencapsulated BTA demonstrate good protective properties according to the potentiodynamic polarization curves and the results of EIS measurements. In addition to these experiments, the protective effect of microcontainers with the CI was estimated by immersing the alloy samples coated with epoxy resin, with and without such containers, in $0.1 \mathrm{M} \mathrm{NaCl}$ solution. Preliminarily, scratches were applied on the coated samples. As shown by micrographs, the entire scratched area of the coating without CPLGA-BTA particles was strongly corroded within $30 \mathrm{~min}$. In the absence of a $\mathrm{CI}$, the protective epoxy coating peeled off, so that the AMlite alloy became exposed to the corrosive environment and underwent continuous corrosion.

Upon painting with CPLGA-BTA, only one corrosion spot was noticed, while the other areas remained unchanged, like before immersion in the chloride solution. The authors consider this fact as a consequence of the inhibitory effect of BTA released from microcontainers due to an increase in $\mathrm{pH}$ that occurs as a result of the onset of corrosion.

Another example of using encapsulated BTA for the protection of magnesium is given in [39]. For this purpose, halloysite nanotubes (NTH) were used. They were loaded with this $\mathrm{CI}$ and added to the silicate-fluoride electrolyte to obtain coatings on AM50 magnesium alloy (composition in wt.\%: $94.67 \mathrm{Mg}, 4.83 \mathrm{Al}, 0.4 \mathrm{Mn}$ ) by plasma electrolytic oxidation (PEO). For comparison, the protective properties of PEO coatings were investigated by immersing alloy samples in $3.5 \% \mathrm{NaCl}$ solution, while some of the coatings were obtained with NTHs without BTA. To determine the resistance of the coating to defects, scratches were applied to them, and then the sample was scanned using the EIS method. It was found that unloaded NTH increased the scratch resistance of the coating better than BTA-NTH, but in the second case, the corrosion resistance improved due to the self-healing effect. This was due to the formation of a dense $\mathrm{Mg}(\mathrm{OH})_{2}$ film in the areas of corrosion after partial destruction of the coating, which prevented pitting. The authors concluded that NTH particles were incorporated into the PEO coatings through a simple one-step galvanostatic process. They are able to reduce its porosity without affecting the phase composition of the coating, which consists mainly of the $\mathrm{Mg}_{2} \mathrm{SiO}_{4}$ phase. The thickness of the BTA-HTH-PEO coating increases to $d=36.2 \pm 3 \mu \mathrm{m}$ and, in contrast to PEO $(d=30 \pm 2.5 \mu \mathrm{m})$ or NTH-PEO $(d=29.5 \pm 2.5 \mu \mathrm{m})$ coatings, corrosion is uniform and non-local. It showed excellent corrosion resistance suppressing local dissolution: even after the anodic potentiodynamic curves were taken, practically no impedance change of such electrodes was observed. Apparently, this occurs due to the self-healing of coating defects caused by the participation of BTA in the formation of a dense nanocrystalline film of $\mathrm{Mg}(\mathrm{OH})_{2}$.

Chen et al. [40] continued studies of the effect of BTA with $C_{\text {in }}=1-15 \mathrm{~g} / \mathrm{L}$ on the corrosion of the same AMlite alloy in $0.1 \mathrm{M} \mathrm{NaCl}$ solution at $\mathrm{pH}$ 3.0, 7.0, and 10.0. To assess 
the inhibitory effect of BTA on the kinetics of anodic dissolution of the alloy, the authors used electrochemical methods combined with scanning electron and optical microscopy, Xray diffraction, and XPS.

They found that BTA had the ability to impart significant corrosion resistance to AMlite magnesium alloy in a weakly alkaline chloride solution, noting also the possibility of alkalinization of the surface solution layer that occurs if the alloy dissolves in a neutral solution. The protection mechanism of the alloy with BTA differs fundamentally from the corrosion inhibition of $\mathrm{Cu}, \mathrm{Fe}, \mathrm{Zn}$, or $\mathrm{Cu}$-containing $\mathrm{Al}$ alloys where the formation of poorly soluble complexes with metal cations plays an important role. In the case of the protection of magnesium and its alloys, such complexes of BTA with $\mathrm{Mg}^{2+}$ were not found, but it is emphasized that BTA molecules are ionized to $\mathrm{BTA}^{-}$anions in aqueous solutions with an excess of $\mathrm{OH}^{-}$anions, i.e., the solution $\mathrm{pH}$ plays an important role (bulk or local alkalinization). BTA was most efficient in inhibiting the corrosion of AMlite alloy in a weakly alkaline $\mathrm{NaCl}$ solution, i.e., at $\mathrm{pH} 10.0$.

The degree of protection provided by it depended on $C_{\mathrm{BTA}}$. The best inhibition of alloy corrosion in a chloride solution was observed at $C_{\mathrm{BTA}}=15 \mathrm{~g} / \mathrm{L} \mathrm{BTA}$. However, the mechanism of protection against corrosion of a magnesium alloy, in contrast to the passivation of $\mathrm{Cu}$ containing alloys with BTA, is attributed to the fact that $\mathrm{BTA}^{-}$anions act as a nucleating agent that stimulates the formation of a dense and highly crystalline $\operatorname{Mg}(\mathrm{OH})_{2}$ film with a homogeneous nanostructure. It is capable of passivating a magnesium alloy, while the protective effect of this $\mathrm{CI}$ on copper, its alloys, and even $\mathrm{Cu}$-containing aluminum alloys is provided by the aforementioned insoluble $\mathrm{Cu}(\mathrm{I})$-BTA complex formed through $\mathrm{Cu}-\mathrm{N}$ coordination bonds. This mechanism was unexpected but allowed us to hope for the practical application of magnesium alloys as anode materials in such cases where the anode dissolves but can be passivated with a slight change in potential.

The corrosion inhibition of AZ31 magnesium alloy containing, beside magnesium, $3 \%$ $\mathrm{Al}$ and $1 \% \mathrm{Zn}$, in microdefects of the protective coating with 1,2,4-triazole (TA), $\mathrm{F}^{-}$and $\mathrm{Ce}^{3+}$ was studied [41]. Before deposition of a hybrid protective sol-gel film, cleaned substrates were etched for $15 \mathrm{~min}$ in $12 \% \mathrm{HF}$ solution at room temperature, washed with deionized water, and dried for $1 \mathrm{~h}$ at $105^{\circ} \mathrm{C}$. Two hours before the immersion of a sample in the corrosive medium $(0.01 \mathrm{M}$ aqueous solution of $\mathrm{NaCl})$, artificial defects were created on the coating down to the metal substrate, i.e., scratches $150 \mu \mathrm{m}$ wide or round defects $200 \mu \mathrm{m}$ in diameter. The studies were carried out by SVET (scanning vibrating electrode method) and SIET (scanning ion-selective electrode method), for which $\mathrm{Mg}^{2+}$ - and $\mathrm{pH}$-selective microelectrodes were previously developed. The microelectrodes have been characterized in terms of properties important for corrosion protection in order to ensure reliable operation during measurements. The combination of SVET and SIET proved to be a useful approach for studying the corrosion inhibition in microdefects of coated AZ31. According to the results obtained, 1,2,4-triazole at $C_{\mathrm{in}}=0.01 \mathrm{M}$ showed the highest protection efficiency among the CIs studied. The authors came to the conclusion that TA prevented an increase in 
$\mathrm{pH}$ in coating defects, keeping the corrosion of the alloy in them at a very low level for the entire test period.

In another work [42], an anticorrosive coating was studied on ZE41 magnesium alloy. It comprised a PEO layer enriched with TA as the CI and sealed with a new sol-gel coating based on silicon dioxide doped with $\mathrm{TiO}_{2}$. The thickness of the PEO layer was $1.8 \mu \mathrm{m}$, and the thickness of the sol-gel film was $6.3 \mu \mathrm{m}$. Sealing the PEO layer with a sol-gel film significantly improved the protection of ZE41 against corrosion in a corrosive $3 \% \mathrm{NaCl}$ solution. In fact, after 30 days of immersion of sealed samples in this solution, the lowfrequency impedance modulus exceeded $10^{8} \mathrm{Ohm} \cdot \mathrm{cm}^{2}$, and no obvious signs of corrosion were observed. Porous PEO oxide/hydroxide acted as an efficient storage of TA: neither the $\mathrm{CI}$ released into the sol-gel film at the deposition stage, nor the presence of TA in the PEO layer deteriorates the protective properties of the composite coating under the conditions studied. Local SVET measurements on artificially formed defects showed the presence of an active anticorrosive effect for a composite coating containing TA. When the electrode was immersed in the above mentioned $\mathrm{NaCl}$ solution, the corrosion rate decreased 3-100 fold.

In the presence of such a self-healing coating on the alloy, a thin porous PEO layer, in addition to providing a high barrier protection effect, can be successfully used as a reservoir for a CI. In this case, TA is fixed in the immediate vicinity of the base metal where corrosion begins, and its leaching slows down due to the presence of a thin sol-gel coating over the PEO layer.

Unfortunately, under other conditions and, for example, on commercial magnesium (Mg 90 alloy in wt.\%: $99.9 \mathrm{Mg},<0.04 \mathrm{Fe}, 0.03 \mathrm{Mn}, 0.02 \mathrm{Al}, 0.001 \mathrm{Ni},<0.004 \mathrm{Cu},<0.009$ $\mathrm{Si},<0.005 \mathrm{Cl}$ ), corrosion protection with TA was not found to be highly efficient. The protective properties of BTA, 5-chloro-BTA, TA, and a mixture of its derivatives (IFKhAN92) toward commercial magnesium were studied in aqueous buffer solutions with pH 7.4 and 9.2 [43]. Triazole concentrates were prepared by dissolution in water (TA, BTA) or isopropyl alcohol (5-chloro-BTA, IFKhAN-92). A triazole concentrate was added to an electrochemical cell filled with a borate buffer, and then a magnesium electrode was immersed therein. After keeping it for $15 \mathrm{~min}$ until the free corrosion potential $E_{\text {cor }}$ was established, polarization curves were recorded in potentiodynamic mode at a potential sweep rate of $0.2 \mathrm{mV} / \mathrm{s}$. The passivating effect of a CI was estimated not only by the results of polarization measurements in borate solutions, but also by corrosion tests of $\mathrm{Mg} 90$ plates in a heat and moisture chamber after exposure for $10 \mathrm{~min}$ to distilled water containing the $\mathrm{CI}$ under study at temperatures of $t=20$ or $60^{\circ} \mathrm{C}$. The criterion for the passivation efficiency was the time until the appearance of the first corrosion damage on the samples in the chamber operating by the following schedule: $t=40^{\circ} \mathrm{C}$ for $8 \mathrm{~h}$, while for the rest of the day heating was turned off, which led to abundant moisture condensation on the samples.

It was shown that in a neutral buffer containing $10 \mathrm{mmol} / \mathrm{L}$ of triazoles, the values of the initial potential $E_{\mathrm{s}}$ are less negative than in the pure buffer and increase with time

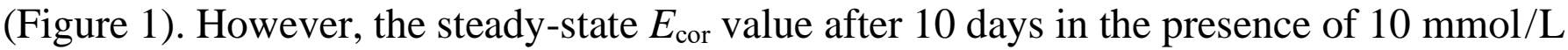


triazoles (with the exception of BTA) remains more negative than in the pure borate buffer. For the longest time, the electrode potential in BTA solutions remains not as negative as in the presence of the other triazoles. Interestingly, in solutions of the most hydrophobic CI (5chloro-BTA and IFKhAN-92), the established values of $E_{\text {cor }}$ are more negative than in the background. This may be due to the inhibition of not only the anodic, but also the cathodic reaction by these CIs. Indeed, as shown by polarization measurements, IFKhAN-92 slows down the cathodic reaction on a magnesium alloy, which is not surprising since this CI is very efficient on various metals in solutions of various acids [44, 45].

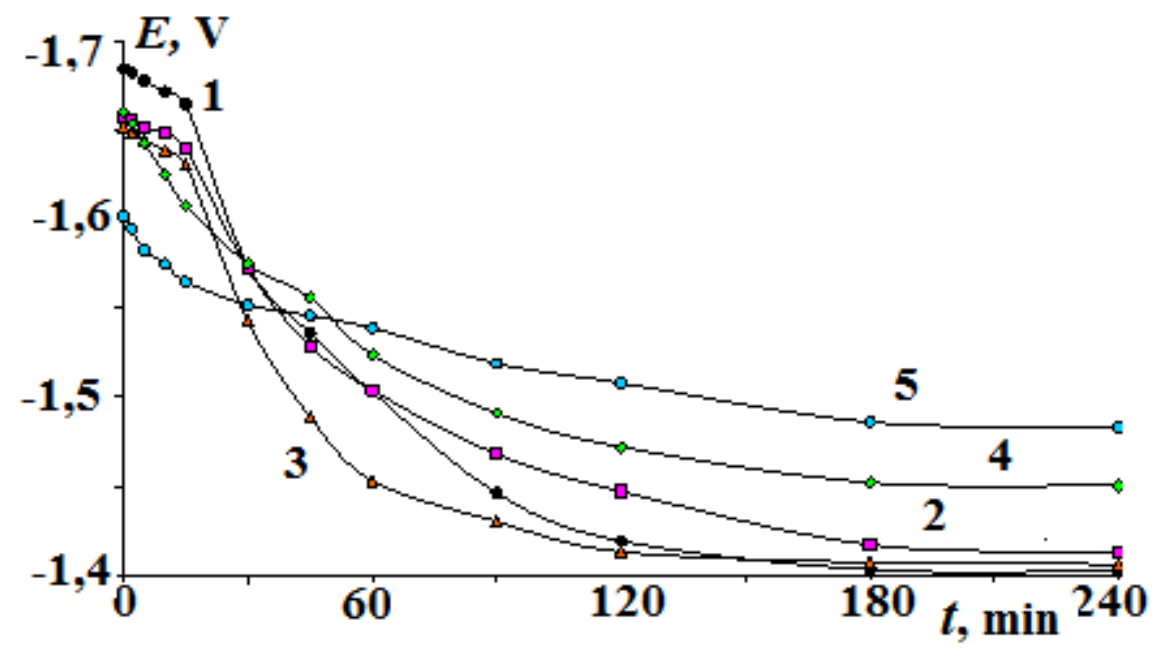

Figure 1. Variation in the electrode potential of magnesium in borate buffer with $\mathrm{pH} 7.4$ without (1) and with addition of $10 \mathrm{mmol} / \mathrm{L}: 2$ - TA; 3 - BTA; 4 - Cl-BTA; 5 - IFKhAN-92 [43].

TA and BTA inhibit the corrosion of magnesium in a neutral borate solution with $\mathrm{pH}$ 7.4 very weakly (Table 1). However, their derivatives (5-chloro-BTA or IFKhAN-92, i.e., a mixture of substituted triazoles) slow down the corrosion of this metal fairly well, though they do not passivate it. Corrosion tests confirmed that IFKhAN-92 can provide a degree of protection $Z=75.8 \%$ in a neutral solution at $C_{\text {in }}=20 \mathrm{mmol} / \mathrm{L}$, but its further improvement is prevented by the limited solubility of the $\mathrm{CI}$ in water, even upon its improvement by adding $10 \%$ isopropanol.

Not only an increase in hydrophobicity but also a decrease in the $\mathrm{p} K_{\mathrm{a}}$ of these $\mathrm{NH}$-acids makes a positive contribution to an increase in the protection of magnesium by triazoles. In a weakly alkaline borate solution with a $\mathrm{pH}$ of 9.2, the corrosion rate of magnesium decreases to $3.91 \mathrm{~g} / \mathrm{m}^{2}$.day, and at $C_{\text {in }}=10 \mathrm{mmol} / \mathrm{L}$ of 5-chloro-BTA and IFKHAN-92, it is 0.38 and $0.39 \mathrm{~g} / \mathrm{m}^{2} \cdot$ day, respectively, with $Z=90.3$ and $90.0 \%$. This testifies to the advantage of the protective action of triazolate anions toward magnesium compared to the molecules of the same CIs.

This work shows yet another option for increasing the protection of magnesium with triazoles, namely, by combined use of IFKhAN-92 with anionic CIs, for example, the sodium salt of dioctyl ester of phosphoric acid, DOPh (Table 1). It was found that the mixed CI 
comprising $1.0 \mathrm{mmol} / \mathrm{L}$ IFKHAN-92 $+1.0 \mathrm{mmol} / \mathrm{L} \mathrm{DOPh}$ reduces the corrosion rate of magnesium in a borate solution with $\mathrm{pH} 7.4$ to $0.14 \mathrm{~g} / \mathrm{m}^{2} \cdot \mathrm{h}$, i.e., $Z$ reaches $97.7 \%$.

Table 1. Results of corrosion tests of commercial Mg in borate solutions containing CIs. The duration of the tests is $1 \mathrm{~h}[43]$.

\begin{tabular}{|c|c|c|c|}
\hline No. & Solution composition & $K, g / m^{2} \cdot h$ & $Z, \%$ \\
\hline 1. & Borate buffer $\mathrm{pH} 7.4$ & 6.20 & - \\
\hline \multirow{2}{*}{2.} & Same +TA $10 \mathrm{mmol} / \mathrm{L}$ & 6.28 & -1.2 \\
\hline & Same +TA $30 \mathrm{mmol} / \mathrm{L}$ & 5.89 & 5.0 \\
\hline 3. & Same +BTA $10 \mathrm{mmol} / \mathrm{L}$ & 6.08 & 1.9 \\
\hline 4. & Same +5-chloro-BTA $10 \mathrm{mmol} / \mathrm{L}$ & 3.48 & 43.9 \\
\hline \multirow{2}{*}{5.} & Same +IFKhAN-92 10 mmol/L & 1.84 & 70.3 \\
\hline & Same +IFKhAN-92 20 mmol/L & 1.50 & 75.8 \\
\hline 6. & $\begin{array}{c}\text { Same }+1 \mathrm{mmol} / \mathrm{L} \mathrm{IFKhAN}-92+1 \mathrm{mmol} / \mathrm{L} \\
\text { DOPh }\end{array}$ & 0.14 & 97.7 \\
\hline 7. & Borate buffer $\mathrm{pH} 9.2$ & 3.91 & - \\
\hline \multirow{3}{*}{8.} & Same +5 -chloro-BTA $1.0 \mathrm{mmol} / \mathrm{L}$ & 1.70 & 56.5 \\
\hline & Same +5 -chloro-BTA $5.0 \mathrm{mmol} / \mathrm{L}$ & 0.87 & 77.7 \\
\hline & Same +5-chloro-BTA $10.0 \mathrm{mmol} / \mathrm{L}$ & 0.38 & 90.3 \\
\hline 9. & Same +IFKhAN-92 $1 \mathrm{mmol} / \mathrm{L}$ & 2.44 & 37.6 \\
\hline 10. & Same +IFKhAN-92 $5 \mathrm{mmol} / \mathrm{L}$ & 1.26 & 67.8 \\
\hline 11. & Same +IFKhAN-92 $10 \mathrm{mmol} / \mathrm{L}$ & 0.39 & 90.0 \\
\hline
\end{tabular}

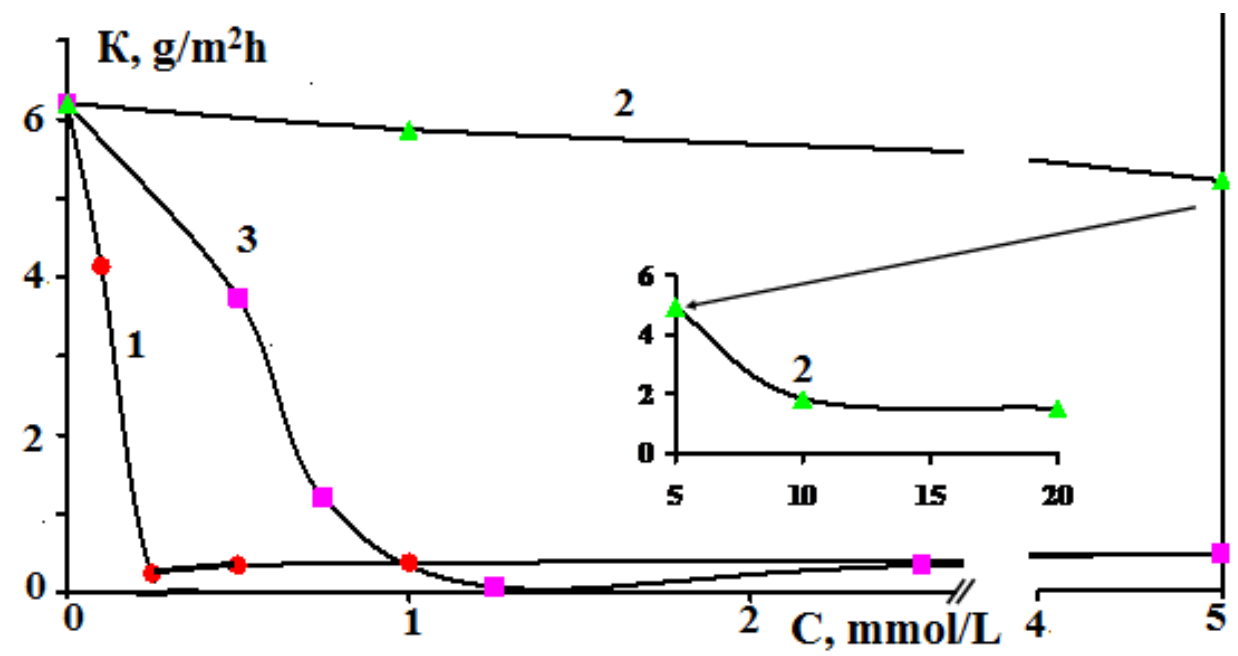

Figure 2. Plot of the corrosion rate of magnesium in a borate solution with $\mathrm{pH} 7.4 \mathrm{vs}$. concentration: 1 - DOPh, 2 - IFKhAN-92, 3 - IFKHAN-92 + DOPh mixture (4:1) [47]. 
As follows from the results of corrosion tests presented in Figure 2, DOPh is a significantly more efficient CI of magnesium than IFKhAN-92 itself, and its small addition to this triazole dramatically increases the efficiency of magnesium protection in a neutral borate buffer. This mixed CI is even capable of completely suppressing magnesium corrosion at low $C_{\mathrm{in}}$. At the component ratio DOPh:IFKhAN-92=1:4, the consumption of the substituted triazole sharply decreases and the value of $Z_{\text {mix }}$ increases compared to $Z_{\mathrm{DOPh}}$ provided at the same $C_{\text {in }}$. In a neutral buffer, the advantage of the mixture over both of its components is also observed with an increase in the fraction of DOPh in it. In fact, at $C_{\text {in }}=1.0 \mathrm{mmol} / \mathrm{L}$ DOPh provides $Z=94 \%$, IFKhAN-92 provides $3.5 \%$, and their mixture provides $97.7 \%$, which is higher than even $5 \mathrm{mmol} / \mathrm{L}$ DOPh does $(Z=92.7 \%)$. In a weakly alkaline medium, this was noted only at low $C_{\mathrm{DOPh}}<0.25 \mathrm{mmol} / \mathrm{L}$, while with its increase, $\mathrm{DOPh}$ is more efficient than the mixture [43].

Table 2. Effect of the duration of exposure of commercial magnesium to a borate buffer solution with $\mathrm{pH} 7.4$ without and with additions of CI on its corrosion rate [43].

Solution composition, mmol/L:

\begin{tabular}{|c|c|c|c|c|}
\hline & & & & \\
\hline & 0.5 & 1.0 & 4.0 & 12.0 \\
\hline Borate buffer & 5.60 & 6.20 & 5.74 & 5.51 \\
\hline Same + $1.0 \mathrm{mmol} / \mathrm{L}$ IFKhAN-92 & 5.30 & 5.88 & 5.34 & 5.24 \\
\hline Same $+0.25 \mathrm{mmol} / \mathrm{L} \mathrm{DOPh}$ & 0.18 & 0.24 & 0.31 & 1.88 \\
\hline Same $+0.25 \mathrm{mmol} / \mathrm{L} \mathrm{DOPh}+\mathrm{IFKhAN}-921.0 \mathrm{mmol} / \mathrm{L}$ & 0.06 & 0.07 & 0.12 & 1.67 \\
\hline $\mathrm{Same}+0.25 \mathrm{mmol} / \mathrm{L} \mathrm{DOPh}+\mathrm{IFKhAN}-924.0 \mathrm{mmol} / \mathrm{L}$ & - & 0.27 & - & 2.95 \\
\hline Same + 1.0 mM DOPh + IFKhAN-92 $1.0 \mathrm{mmol} / \mathrm{L}$ & - & 0.14 & 0.15 & 2.83 \\
\hline Same + $1.0 \mathrm{mM} \mathrm{DOPh}+$ IFKhAN-92 $4.0 \mathrm{mmol} / \mathrm{L}$ & - & 0.45 & 0.76 & 2.43 \\
\hline
\end{tabular}

However, it was noted that the high degree of magnesium protection by the CIs studied does not last long. In the buffer itself with $\mathrm{pH} 7.36$, the corrosion rate passes through a small maximum, i.e., it increases in the time period from 0.5 to $4.0 \mathrm{~h}$, which is probably due to the destruction of the oxide layer formed in air, and then decreases due to the protective properties of the formed film of gray corrosion products. After $12.0 \mathrm{~h}$, it apparently reaches a constant value of $K=5.53 \pm 0.02 \mathrm{~g} / \mathrm{m}^{2} \cdot \mathrm{h}$ (Table 2). Addition of $1.0 \mathrm{mmol} / \mathrm{L}$ IFKhAN-92 slightly reduces the corrosion rate, although its dependence on the test duration differs little from that in the initial buffer. A four times smaller addition of DOPh reduces the corrosion rate more efficiently, but its inhibitory effect changes over time: at first it slowly weakens and then drops abruptly. It is essential that the sharp drop in the protective effect of DOPh cannot be explained by the fact that $C_{\mathrm{DOPh}}$ is simply small and insufficient to block the entire metal surface. This is indicated by the fact that an increase in $C_{\mathrm{DOPh}}$ above $0.25 \mathrm{mmol} / \mathrm{L}$ by itself (at the same test time) does not increase but rather decreases the $Z$ value of the inhibitor. It is possible that DOPh, like organic complexones, forms water-soluble compounds with 
the cations of the metal being protected with an increase in $C_{\text {in }}$ in solutions [46]. This prevents the formation of a protective hydroxide-oxide film on magnesium, and the corrosion of samples after 12 hours is local in nature in this case.

To improve the protection of magnesium by IFKhAN-92, the use of relatively small $\mathrm{DOPh}$ additives was attempted [43]. It was found that in the first 4 hours, the formulation of $0.25 \mathrm{mmol} / \mathrm{L}$ with $1.0 \mathrm{mmol} / \mathrm{L}$ IFKHAN-92 exhibits high protective properties $(Z=97.9 \%)$ surpassing that of DOPh itself at its optimal concentration. However, after 12 hours, the $Z$ value decreases to $69.7 \%$. Unfortunately, an increase in $C_{\mathrm{DOPh}}$ or $C_{\mathrm{IFKHAN}-92}$ in this formulation noticeably impairs the efficiency of a mixed CI, which is apparently due to the competition in the adsorption of its constituents with formation of an oxide-hydroxide film.

In a weakly alkaline solution, the protective effect of the mixed CI changes. The best protection of magnesium in a solution with a $\mathrm{pH}$ of 9.2 is achieved at a higher total $C_{\text {in }}$ $(1.5 \mathrm{mmol} / \mathrm{L} \mathrm{DOPh}+6.0 \mathrm{mmol} / \mathrm{L}$ IFKhAN-92) than in a neutral solution. However, the $Z$ value decreases more slowly over time (from $95.4 \%$ in 1 hour of testing to $92.9 \%$ in 12 hours, whereas in a solution with $\mathrm{pH} 7.4$ at the same $C_{\text {in }}, Z$ decreases from 92.6 to $82.6 \%$ ). In view of this, magnesium passivation was carried out in aqueous solutions with $C_{\text {in }}=5.0$ $7.5 \mathrm{mM}$ at various $\mathrm{pH}$ and $t$ values (Table 3 ).

Table 3. Results of tests in a heat and moisture chamber of technical $\mathrm{Mg}$, pretreated in aqueous solutions of CI attired at $V=0.3 \mathrm{~m} / \mathrm{s}[43]$.

\begin{tabular}{ccccc}
\hline No. The composition of the passivating solution & $\mathbf{p H}$ & $\begin{array}{c}\text { Treatment } \\
\text { temperature, } \\
{ }^{\circ} \mathbf{C}\end{array}$ & $\begin{array}{c}\boldsymbol{\tau} \text { before the first } \\
\text { indications of } \\
\text { corrosion, } \mathbf{h}\end{array}$ \\
\hline 1 & Without treatment & - & - & 0.5 \\
2 & $5.0 \mathrm{mmol} / \mathrm{L} \mathrm{DOPh}$ & 9.2 & 20 & 2.0 \\
3 & $5.0 \mathrm{mmol} / \mathrm{L} \mathrm{K} \mathrm{K}_{2} \mathrm{CrO}_{4}$ & Same & Same & 3.0 \\
4 & $1.0 \mathrm{mmol} / \mathrm{L} \mathrm{DOPh}+4.0 \mathrm{mmol} / \mathrm{L} \mathrm{IFKhAN-92}$ & 7.4 & 60 & 2.0 \\
& Same & 9.2 & 20 & 2.5 \\
5 & Same $+1.0 \mathrm{mmol} / \mathrm{L}$ VTMS & Same & 60 & 3.0 \\
& Same $+5.0 \mathrm{mmol} / \mathrm{L}$ VTMS & 7.4 & Same & 2.5 \\
& Same & 9.2 & 20 & 3.5 \\
7 & Same & Same & 60 & 4.0 \\
& Same $+10.0 \mathrm{mmol} / \mathrm{L}$ VTMS & Same & Same & 3.0 \\
\hline
\end{tabular}

Magnesium samples placed in a heat and moisture chamber (100\% relative air humidity, daily moisture condensation) began to undergo pitting corrosion after $30 \mathrm{~min}$, and it rapidly increased in time. Treatment of samples in a neutral $5 \mathrm{mmol} / \mathrm{L} \mathrm{DOPh}$ solution, regardless of $t$, protected them from corrosion for $\tau=1.5 \mathrm{~h}$. If passivation is carried out in 
the same solution with $\mathrm{pH} 9.2$, then $\tau$ can be increased to $2.0 \mathrm{~h}$. These results show that such passivation is inferior in efficiency to chromate passivation that provides $\tau=3.0 \mathrm{~h}$.

Treatment of magnesium in a solution of the mixed CI containing $1.0 \mathrm{mmol} / \mathrm{L} \mathrm{DOPh}$ $+4 \mathrm{mmol} / \mathrm{L}$ IFKHAN-92, which is best to perform at room temperature and $\mathrm{pH} 9.2$ $(\tau=2.5 \mathrm{~h})$, also fails to reach the efficiency of chromate passivation. To further improve the passivation of magnesium with aqueous solutions of CIs [43], vinyltrimetoxysilane (VTMS) was added to them, although it does not possess inhibitory properties by itself. A chemical conversion of VTMS results in hardly soluble siloxane nanoscale layers on the metal surface, which can increase the stability of adsorption films formed by a CI. It was found to be sufficient to add as little as $1.0 \mathrm{mM}$ VTMS to an immiscible solution of the mixed CI $(5.0 \mathrm{mM})$ with a $\mathrm{pH}$ of 9.2 for increasing $\tau$ to $2.5 \mathrm{~h}\left(t=20^{\circ} \mathrm{C}\right)$ or $3.0 \mathrm{~h}\left(t=60^{\circ} \mathrm{C}\right)$. An increase in $C_{\text {VTMS }}$ to $5.0 \mathrm{mM}$ makes the efficiency of passivation treatment of magnesium with the mixed CI $\left(t=20^{\circ} \mathrm{C}, \tau=3.5 \mathrm{~h} ; t=60^{\circ} \mathrm{C}, \tau=4.0 \mathrm{~h}\right)$ higher than that achieved by chromate solutions. It should be noted that a further increase in VTMS may not only fail to improve the passivating effect but even weaken it, as it can be seen in the case of adding $10 \mathrm{mmol} / \mathrm{L}$ VTMS.

The conclusion was made that addition of VTMS to the mixed CI along with optimization of the magnesium treatment mode (stirring, temperature, $C_{\text {in }}$ ) makes it possible to create an ultrathin protective organic coating on the metal surface. It increases the time before the appearance of signs of corrosion on magnesium 8-9 fold and is, at least, not inferior in the efficiency of protection by chromate treatment.

Another CI of the triazole class and formulations based on it were also studied by us on commercial magnesium [47]. However, in this work, we used borate buffer solutions with $\mathrm{pH} 7.4$ and 9.2 as the background solutions, but with $10 \mathrm{mmol} / \mathrm{L} \mathrm{NaCl}$ to increase their corrosivity. The duration of corrosion tests in these solutions varied from 1.0 to 12 hours. The passivating effect of the $\mathrm{CI}$ was also estimated from the results of corrosion tests of $\mathrm{Mg}$ 90 plates in a heat and moisture chamber after immersing them for $10 \mathrm{~min}$ in distilled water containing the $\mathrm{CI}$ under study. In this case, the solution was stirred on a magnetic stirrer at a speed of $V \approx 0.3 \mathrm{~m} / \mathrm{s}, \mathrm{pH} 7.4$ or $9.2, t=20$ or $60^{\circ} \mathrm{C}$.

As one can see from the anodic polarization curves in Figure 3, the mixed CI consisting of 5-chloro-BTA and DOPh (1:4) increases the polarizability of the magnesium electrode, although there is no passive potential region typical of passivators such as potassium chromate [47] or sodium oleate [21-24]. The $E_{\text {cor }}$ of magnesium in a borate buffer with $\mathrm{pH} 9.2$ containing $10 \mathrm{mmol} / \mathrm{L} \mathrm{NaCl}$ upon addition of $C_{\mathrm{in}}=10 \mathrm{mmol}$ of the mixed $\mathrm{CI}$ increases by $0.06 \mathrm{~V}$.

Corrosion tests also confirmed that with an increase in $C_{\mathrm{DOPh}}$, it can have an adverse effect on the formation of a protective hydroxide-oxide film on magnesium. In view of this, small DOPh concentrations are promising for improving the protection of magnesium by 5chloro-BTA, but even in this case, the protection decreases over time. For example, in onehour tests in a weakly alkaline buffer, the most efficient composition of the mixed inhibitor 
(4.0 mM DOPh $+16.0 \mathrm{mM}$ 5-chloro-BTA) provides $Z=94.4 \%$, but this value decreases to $86.4 \%$ after 12 hours.

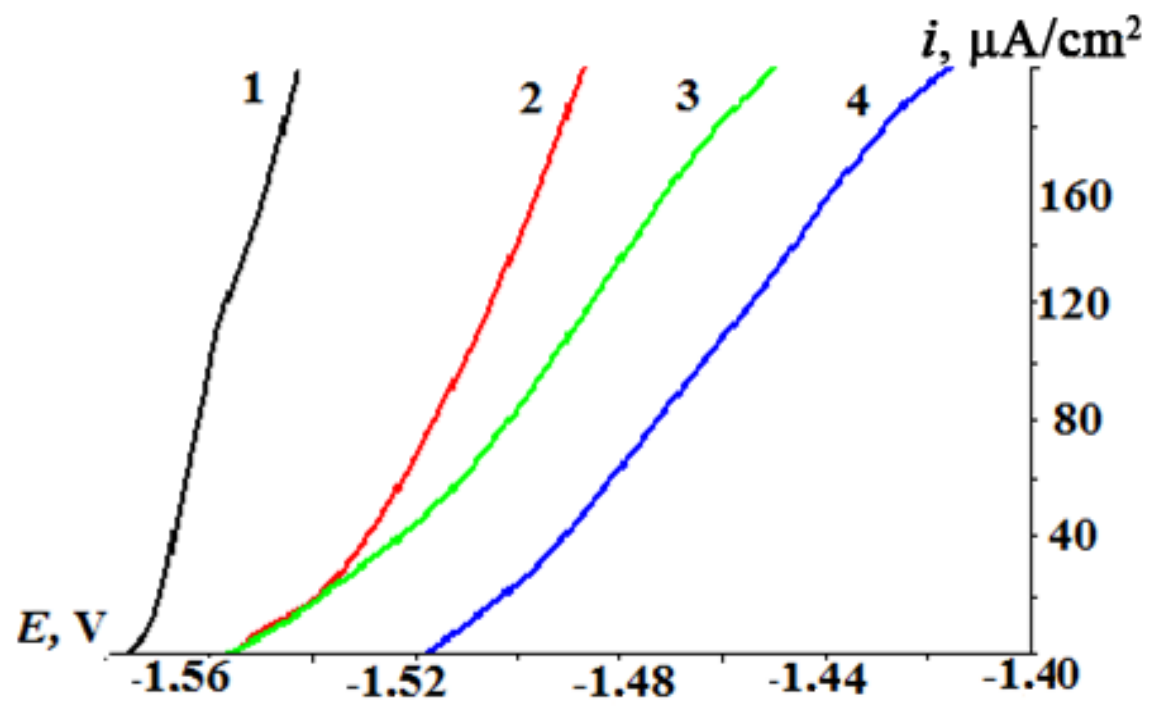

Figure 3. Anodic polarization curves of magnesium in a borate solution containing $10 \mathrm{mM}$ $\mathrm{NaCl}$ with $\mathrm{pH} 9.2$ without (1) and with addition of a mixture of 5-chloro-BTA + DOPh (in $\mathrm{mmol} / \mathrm{L}): 2-0.25+1.0 ; 3-1.0+4.0 ; 4-2.0+8.0$ [47].

Table 4. Results of corrosion tests of magnesium in a borate solution containing $10 \mathrm{mM} \mathrm{NaCl}$ with $\mathrm{pH} 9.2$ and $\mathrm{CI}$ additive.

Solution composition (in $\mathrm{mmol} / \mathrm{L}$ )

Corrosion rate of magnesium $\left(\mathrm{g} / \mathrm{m}^{2} \cdot \mathrm{h}\right)$ and degree of its protection (\%) over the test duration (h):

\begin{tabular}{ccccc}
\cline { 2 - 5 } & $\boldsymbol{K}$ & $\boldsymbol{Z}, \boldsymbol{\%}$ & $\boldsymbol{K}^{\prime}$ & \multicolumn{2}{c}{$\boldsymbol{Z}^{\prime}, \boldsymbol{\%}$} \\
\hline Borate solution +10 NaCl (BS) & 3.23 & - & 2.06 & - \\
BS +5.0 VTMS & 1.87 & 42.1 & 1.93 & 6.3 \\
4.0 5-chloro-BTA + 1.0 DOPh + 1.0 VTMS & 0.30 & 90.7 & 0.34 & 83.5 \\
4.0 5-chloro-BTA + 1.0 DOPh + 5.0 VTMS & 0.29 & 91.0 & 0.32 & 84.5 \\
8.0 5-chloro-BTA + 2.0 DOPh + 5.0 VTMS & 0.22 & 93.2 & 0.29 & 85.9 \\
12.0 5-chloro-BTA + 3.0 DOPh + 5.0 VTMS & 0.18 & 94.4 & 0.24 & 88.3 \\
16.0 5-chloro-BTA + 4.0 DOPh + 5.0 VTMS & 0.14 & 95.7 & 0.22 & 89.3 \\
\hline
\end{tabular}

Note. $K$ - corrosion rate over 1 hour, $K^{\prime}$ - over 12 hours.

VTMS has a beneficial effect on the protection of magnesium by mixed CI in a solution containing $10 \mathrm{mmol} / \mathrm{L} \mathrm{NaCl}$ (Table 4). VTMS itself at $C_{\text {in }}=5 \mathrm{mmol} / \mathrm{L}$ in a short-term test $(1 \mathrm{~h})$ slows down the corrosion rate with $Z=42.1 \%$, but after 12 hours the protection drops sharply to $Z^{\prime}=6.3 \%$. If we add as little as $1 \mathrm{mmol} / \mathrm{L}$ VTMS to the mixed CI $(4 \mathrm{mmol} / \mathrm{L} \mathrm{5-}$ chloro-BTA $+1 \mathrm{mmol} / \mathrm{L} \mathrm{DOPh}$ ) in one-hour tests, $Z=90.7 \%$, and although $Z$ decreases after 
12 hours, the decrease is significantly smaller, i.e., to $83.5 \%$. With an increase in the VTMS concentration to $5 \mathrm{mmol} / \mathrm{L}$, the value of $Z$ of the ternary composition slightly increases in one-hour tests but decreases in $12 \mathrm{~h}$ by a smaller value than in the case of the binary CI. By keeping a constant VTMS concentration but increasing $C_{\mathrm{in}}$, it is possible to achieve an even better result. The authors suggested that VTMS is directly incorporated in the protective adsorption layers formed by CI on magnesium, and its ability to form first silanol upon hydrolysis and then siloxane structures stabilizes its protective effect.

Treatment of magnesium with a solution of a ternary formulation of CIs has a better passivating ability than with a binary one, as confirmed by tests in a heat and moisture chamber (GOST 9.054-75). Chromate treatment, regardless of $t$, provided magnesium protection for $3.0 \mathrm{~h}$ (Figure 4a). Passivation treatment of magnesium in a weakly alkaline solution of a mixed CI (4.0 mM 5-chloro-BTA + 1.0 $\mathrm{mM} \mathrm{DOPh})$ provides better protection at $t=20^{\circ} \mathrm{C}(\tau=2.5 \mathrm{~h})$ than at $60^{\circ} \mathrm{C}$. It surpasses a similar treatment with a solution of $5 \mathrm{mmol} / \mathrm{L} \mathrm{DOPh}$ but is inferior to chromate passivation. In order to achieve an equal efficiency, the $C_{\text {mix }}$ has to be increased fourfold. Obviously, such a high concentration of the binary CI is not very promising; therefore, the VTMS was also added to increase the passivation efficiency. This decision is supported by the fact of VTMS chemical conversion, which lead to the formation of stabilizing siloxane layers on the surface of metals.
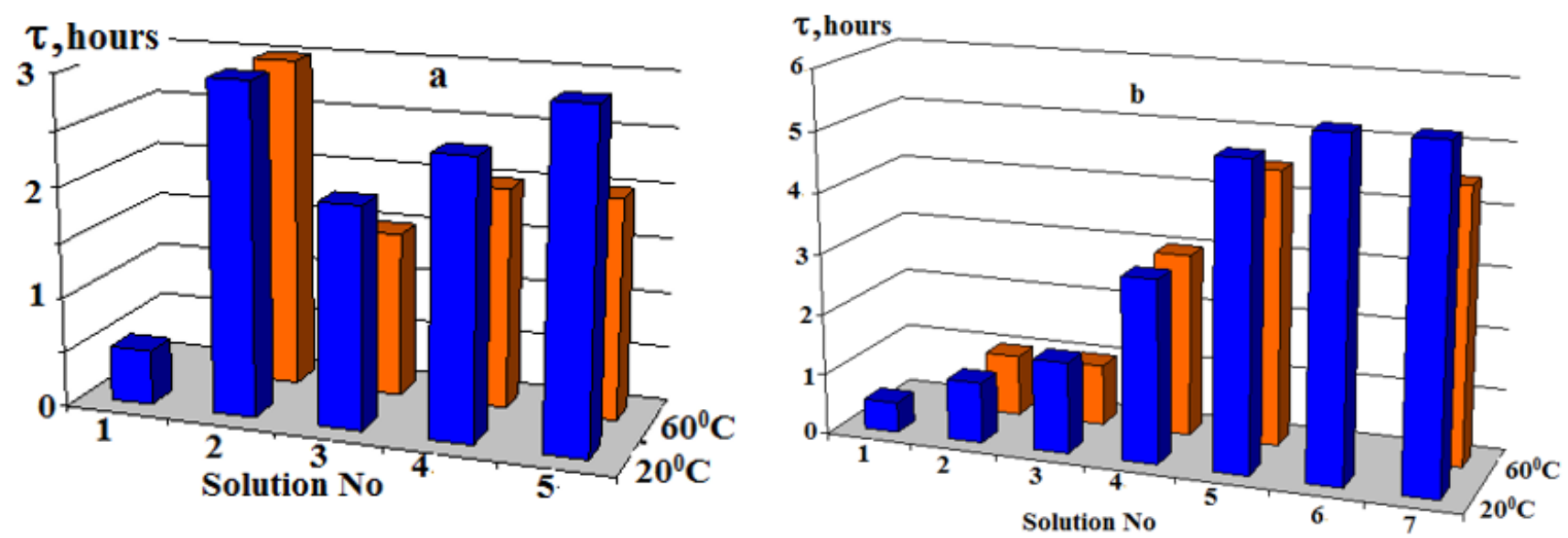

Figure 4. Dependence of the time until the appearance of the first corrosion damage on magnesium, placed in a heat and moisture chamber without (1) and with preliminary treatment (2-7) in a stirred $(V=0.3 \mathrm{~m} / \mathrm{s})$ solution with $\mathrm{pH} 9.2$ and $t=20$ or $60^{\circ} \mathrm{C}$ containing (in mmol): (a) 2 - 5.0 $\mathrm{K}_{2} \mathrm{Cr}_{2} \mathrm{O}_{7} ; 3$ - 5.0 DOPh; 4 - 4.0 5-chloro-BTA + $1.0 \mathrm{DOPh} ; 5$ - 16 5-chloro-BTA + 4 DOPh; (b): 2 - 5.0 VTMS; 3 - 10 VTMS; 4 - 1.0 DOPh + 5.0 VTMS; 5 - 4.0 5-chloro-BTA + 1.0 DOPh + 5.0 VTMS; 6 - 12.0 MM 5-chloro-BTA + 3.0 DOPh + 5.0 VTMS; 7 - 4.05 chloro-BTA + 1.0 DOPh + 10.0 VTMS [47].

It was found that addition of $5.0 \mathrm{mmol} / \mathrm{L}$ VTMS to a mixed CI solution $(4 \mathrm{mmol} / \mathrm{L} \mathrm{5-}$ chloro-BTA $+1.0 \mathrm{mmol} / \mathrm{L} \mathrm{DOPh}$ ) used for magnesium treatment provides corrosion prevention for $5 \mathrm{~h}$, or $5.5 \mathrm{~h}$ at $10 \mathrm{mmol} / \mathrm{L}$ VTMS (Figure 4b). Consequently, comparison of the results presented in Figure 5 shows that the three-component CI generally increases the 
time before the appearance of the first corrosion signs on magnesium by a factor of 10 , while the efficiency of its treatment with solutions is 1.5-2 times higher than that of chromate treatment.
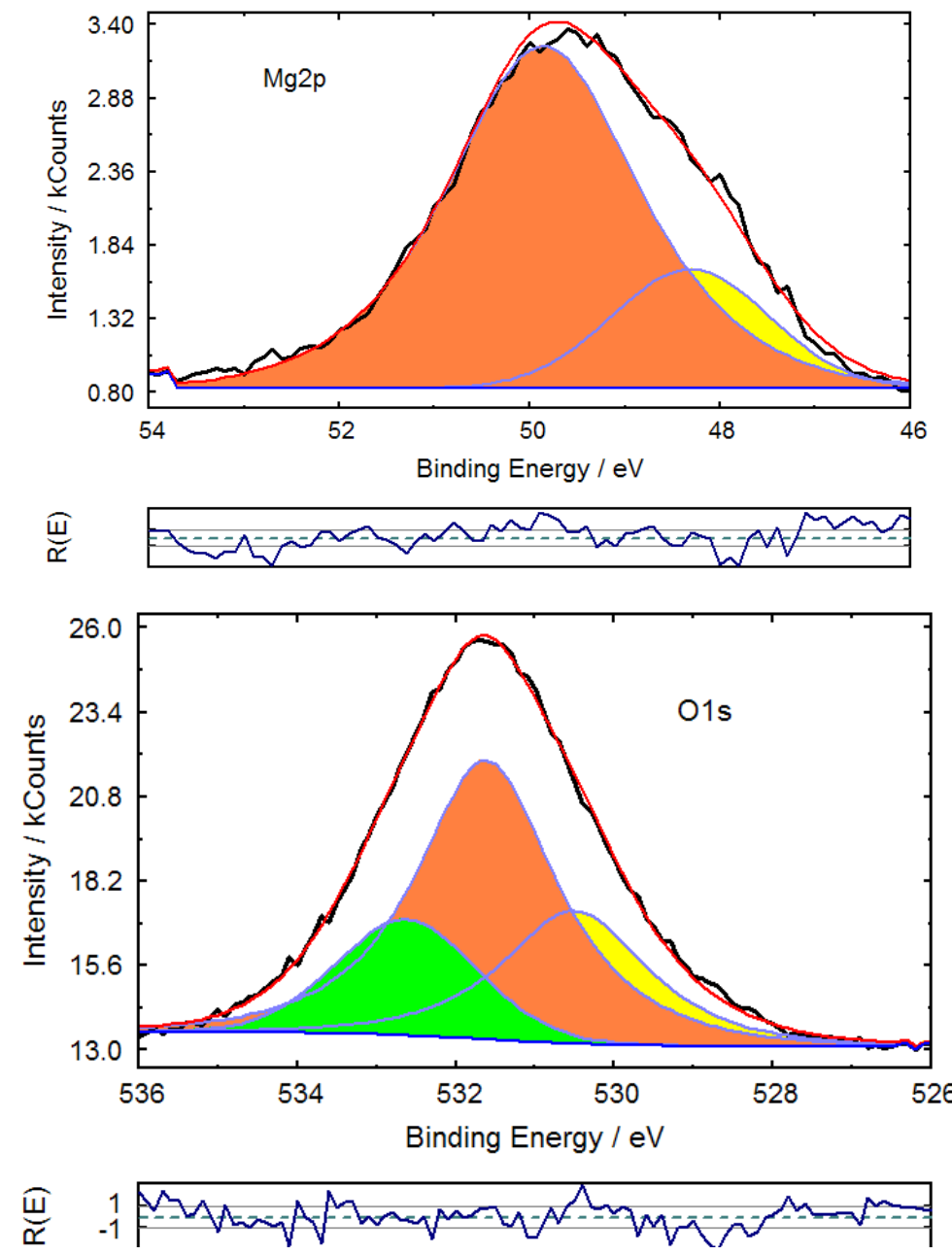

Figure 5. $\mathrm{Mg} 2 \mathrm{p}$ (a) and O1s (b) XPS spectra of the surface of magnesium samples kept in water [47].

Studies of the passive surface by XPS showed that magnesium samples kept in solutions of 5-chloro-BTA and/or DOPh always contained these CIs in the surface layers. After exposure of a sample in pure water, a large amount of $\mathrm{OH}^{-}$was found on its surface in the O1s spectrum. It can be decomposed into three components due to adsorbed water molecules, $\mathrm{OH}^{-}$and oxygen from magnesium oxide (Figure 5). In this case, processing of the peak intensities indicates that the thickness of the mixed magnesium oxide-hydroxide is no more than $5 \mathrm{~nm}$.

After exposure of the samples in solutions of the indicated CIs, the XPS spectra display $\mathrm{N} 1 \mathrm{~s}$ and $\mathrm{Cl} 2 \mathrm{p}$ peaks due to the presence of 5-chloro-BTA and P2p peaks on the surface due to the adsorption of DOPh. However, after ultrasonic washing in isopropyl alcohol, the intensity of these peaks decrease significantly, which shows a large contribution of the 
physical adsorption of these CIs. At the same time, these peaks do not disappear completely, which suggests the presence of chemisorbed organic CI particles that are more strongly bound to magnesium cations. The thickness of such a 5-chloro-BTA layer does not exceed $0.35 \mathrm{~nm}$, which is less than the length of the molecule; therefore, an islet arrangement of molecules is possible where they are oriented vertically with respect to the sample surface. It cannot be ruled out as well that in this case, adjacent nitrogen atoms can be coordinated to two neighboring magnesium cations, as suggested for the adsorption of triazole on copper [48]. In another case, the planes of the molecules can be arranged at an angle to the metal surface and therefore a pseudo monolayer is obtained covering the entire surface of the magnesium oxide-hydroxide layer, which affects the corrosion properties of the protected metal. Upon interaction of DOPh with the magnesium surface and subsequent ultrasonic washing, the thickness of the resulting CI layer can be up to $0.8 \mathrm{~nm}$, which corresponds to its rather dense packing.

Unfortunately, this review lacks sufficiently broad information on the inhibiting and passivating ability of triazoles because it is very scarce in scientific literature. There are several reasons for this. One of them lies in the narrow range of non-toxic and relatively efficient CIs for magnesium alloys. The results of some studies do not give grounds for optimism in continuing the search for efficient CIs suitable for solving the problem of replacing toxic chromates, provided that they are less environmentally hazardous. Note that this problem as applied, for example, to copper and its alloys has been solved in many cases using a number of triazoles [29, 33]. Unfortunately, the triazoles studied cannot be attributed to very efficient CIs for magnesium alloys. Salts of carboxylic acids look more promising in this function.

The remark [49] that "often in the literature there are heterogeneous data describing the effect of one and the same CI on various Mg alloys" is also valid. It was confirmed with extensive studies on more than 150 individual CIs on three types of the metal with various purity and on 6 magnesium alloys (AZ31, AZ91, AM50, WE43, ZE41, and Elektron 21). Comparative tests were carried out in $0.5 \% \mathrm{NaCl}$ solution with adjustment of its initial $\mathrm{pH}$ in the range of 5.5-7.2. The corrosion rate of magnesium and its alloys was determined by measuring the volume of hydrogen evolved in 20 hours of testing.

According to the results of these tests, BTA in most cases stimulated the corrosion of magnesium in such a corrosive chloride solution the stronger the higher the $C_{\mathrm{BTA}}$, while it played the role of a CI only at a very low concentration $(0.5 \mathrm{mmol} / \mathrm{L})$. The situation is no better with TA and 3-amino-TA that do not exhibit a protective effect in the same chloride solution. Also noteworthy is that 5-chloro-BTA also lacks protection under these conditions, whereas in a borate buffer ( $\mathrm{pH}$ 9.2) containing $10 \mathrm{mmol} / \mathrm{L} \mathrm{NaCl}$, it not only exhibits inhibitory properties toward commercial magnesium but is also able to improve the passivating properties in a mixture with other CIs [47]. Of course, studies and search for new efficient CIs of the triazole class for magnesium alloys should not be stopped, but they should be carried out in less corrosive media than chloride solutions, and it is more likely to obtain 
efficient CIs using formulations of triazoles with other CIs, for example, carboxylates, phosphonates, or silanes.

At the same time, a continuation of studies on triazoles may open up new possibilities for their use. Recently, 5-chloro-BTA was studied for the first time as a chamber inhibitor in a development of a new method of vapor-phase protection of metals by short-term treatment with vapors of low-volatile organic inhibitors at elevated temperatures in a closed volume ("chamber treatment") [50]. It was found that upon one-hour exposure of MA8 magnesium alloy at $150^{\circ} \mathrm{C}$ in a dry atmosphere containing no inhibitor vapors, the thickness of the hydrophilic oxide-hydroxide film $(d=3.9-4.0 \mathrm{~nm})$ practically does not increase, and the samples quickly corrode when exposed to a humid atmosphere with periodic moisture condensation. On the contrary, a similar chamber treatment of samples but in the presence of 5-chloro-BTA vapors increases the stability of the samples 18-fold. XPS studies of their surfaces proved the presence of a thin layer of chemisorbed CI $(d=0.7 \mathrm{~nm})$ formed on the oxide-hydroxide layer of magnesium $(d=5.2 \mathrm{~nm})$ and acquisition of hydrophobic properties with a contact angle $\Theta=102^{\circ} \mathrm{C}$ by the surface.

\section{Conclusion}

The CIs of triazole class are significantly less efficient in protecting magnesium and its alloys in neutral media than in inhibiting the corrosion of $\mathrm{Cu}, \mathrm{Zn}, \mathrm{Al}$, their alloys, and steels. However, it should be remembered that organic CIs and especially triazoles have been less studied in the protection of magnesium alloys.

Despite the fact that direct comparison in aqueous solutions shows that CIs of this class most widely studied on many metals and alloys, such as BTA, TA and 3-amino-TA, do not provide better protection against corrosion of $\mathrm{Mg}$ or its alloys than carcinogenic chromates, this is not the fact in certain cases. In fact, addition of BTA to a silicate-borate anodizing electrolyte can replace chromate, increasing the resistance of the anodic film on AZ31B alloy, making it thicker and more compact. Another possibility of efficient $\mathrm{Mg}$ protection with BTA involves loading it into porous particles of a copolymer of lactic and glycolic acid that are then sprayed onto the surface of AMlite magnesium alloy, followed by coating the layer of encapsulated CI with an epoxy resin. The encapsulation of BTA in halloysite nanotubes (NTH) and addition of the latter to a silicate-fluoride electrolyte for PEO of AM50 alloy reduced the porosity of the resulting coatings, prevented the occurrence of local corrosion, and provided excellent alloy resistance even in $3 \% \mathrm{NaCl}$. (The incorporation of other triazoles, TA for example, into a PEO coating is possible). The mechanism of protection of magnesium alloys with triazoles in these and some other cases, for example, in a weakly alkaline solution ( $\mathrm{pH} \mathrm{10),} \mathrm{differs} \mathrm{from} \mathrm{the} \mathrm{protection} \mathrm{of} \mathrm{other} \mathrm{metals} \mathrm{by} \mathrm{these}$ compounds where hardly soluble complexes with their cations are formed. Here, for example, BTA plays the role of a nucleating agent promoting the formation of a dense and highly crystalline $\operatorname{Mg}(\mathrm{OH})_{2}$ film with a homogeneous nanostructure, which passivates the alloy. 
Another aspect of the mechanism of the protection of $\mathrm{Mg}$ alloys with triazoles from corrosion is the blocking of $\mathrm{Cu}$-containing intermetallic compounds, impurities of iron and other metals that are more electropositive than $\mathrm{Mg}$, which initiate local dissolution of the alloys.

The passivating ability of BTA and TA with respect to commercial Mg even in weakly alkaline solutions is small, but their derivatives [a mixture of substituted TA (IFKHAN-92) and 5-chloro-BTA], especially in combination with dioctyl phosphate CI, are more efficient. An increase in the passivation efficiency can also be achieved by adding VTMS to a mixed $\mathrm{CI}$, which increases the time before the appearance of corrosion foci on $\mathrm{Mg}$ in the heat and moisture chamber 8-9 fold and exceeds the efficiency of chromate protection. According to XPS data, the protection of Mg by these CIs is due to the formation of a thin film on it, which consists of a mixed magnesium oxide-hydroxide with a chemisorbed nearly-monolayer of organic molecules.

\section{References}

1. Corrosion. Handbook, Ed.: L.L. Shreier, Newnes-Butterworths Press, London and Boston, 1977.

2. A. Atrens, G.L. Song, M. Liu, Z. Shi, F. Cao and M.S. Dargusch, Review of recent developments in the field of magnesium corrosion, Adv. Eng. Mater., 2015, 17, no. 3, 400-453. doi: 10.1002/adem.201400434

3. N.T. Kirkland, N. Birbilis and M.P. Staiger, Assessing the corrosion of biodegradable magnesium implants: a critical review of current methodologies and their limitations, Acta Biomater., 2012, 8, 925-936. doi: 10.1016/j.actbio.2011.11.014

4. M. Esmaily, J.E. Svensson, S. Fajardo, N. Birbilis, G.S. Frankel, S. Virtanen, R. Arrabal, S. Thomas and L.G. Johansson, Fundamentals and advances in magnesium alloy corrosion, Prog. Mater. Sci., 2017, 89, 92-193. doi: 10.1016/j.pmatsci.2017.04.011

5. F. Cao, G.-L. Song and A. Atrens, Corrosion and passivation of magnesium alloys, Corros. Sci., 2016, 111, 835-845. doi: 10.1016/j.corsci.2016.05.041

6. G. Williams, N. Birbilis and H.N. McMurray, The source of hydrogen evolved from a magnesium anode, Electrochem. Commun., 2013, 36, 1-5. doi: $\underline{10.1016 / \text { j.elecom.2013.08.023 }}$

7. L. Yang, G. Liu, L. Ma, E. Zhang, X. Zhou and G. Thompson, Effect of iron content on the corrosion of pure magnesium: Critical factor for iron tolerance limit, Corros. Sci., 2018, 139, 421-429. doi: 10.1016/j.corsci.2018.04.024

8. G.-L. Song and A. Atrens, Corrosion mechanisms of magnesium alloys, Adv. Eng. Mater., 1999, 1, no. 1, 11-33. doi: 10.1002/(SICI)1527-2648(199909)1:1<11::AIDADEM11>3.0.CO;2-N

9. G. Song, S. Hapugoda and D. StJohn, Degradation of the surface appearance of magnesium and its alloys in simulated atmospheric environments, Corros. Sci., 2007, 49, 1245-1265. doi: $10.1016 /$ j.corsci.2006.07.005 
10. T. Zhang, C. Chena, Y. Shao, G. Meng, F. Wang, X. Li and C. Dong, Corrosion of pure magnesium under thin electrolyte layers, Electrochim. Acta, 2008, 53, 7921-7931. doi: 10.1016/j.electacta.2008.05.074

11. D. Huang, J. Hu, G.-L. Song and X. Guo, Inhibition effect of inorganic and organic inhibitors on the corrosion of $\mathrm{Mg}-10 \mathrm{Gd}-3 \mathrm{Y}-0.5 \mathrm{Zr}$ alloy in an ethylene glycol solution at ambient and elevated temperatures, Electrochim. Acta, 2011, 56, 10166-10178. doi: 10.1016/j.electacta.2011.09.002

12. J. Hu, D. Huang, G.-L. Song and X. Guo, The synergistic inhibition effect of organic silicate and inorganic $\mathrm{Zn}$ salt on corrosion of Mg-10Gd-3Y magnesium alloy, Corros. Sci., 2011, 52, 4093-4101. doi: 10.1016/j.corsci.2011.08.017

13. I. Stary, Ekstraktsiya khelatov (Extraction of chelates), Translated from English by Yu.A. Zolotov, 1966, Moscow, Mir, 392 (in Russian).

14. H. Gao, Q. Li, Y. Dai, F. Luo and H.X. Zhang, High efficiency corrosion inhibitor 8hydroxyquinoline and its synergistic effect with sodium dodecylbenzenesulphonate on AZ91D magnesium alloy, Corros. Sci., 2010, 52, 1603-1609. doi: $\underline{10.1016 / j . c o r s c i .2010 .01 .033}$

15. J. Hu, D. Huang, G. Zhang, G.-L. Song and X. Guo, A Study on Tetraphenylporphyrin as a Corrosion Inhibitor for Pure Magnesium, Electrochem. Solid-State Lett., 2012, 15, no. 6, C13-C15. doi: 10.1149/2.021206esl

16. J. Hu, D. Huang, G. Zhang, G.-L. Song and X. Guo, Research on the inhibition mechanism of tetraphenylporphyrin on AZ91D magnesium alloy, Corros. Sci., 2012, 63, 367-378. doi: 10.1016/j.corsci.2012.06.021

17. Y. Liu, Z. Yu, S. Zhou and L. Wu, Self-assembled monolayers on magnesium alloy surfaces from carboxylate ions, Appl. Surf. Sci., 2006, 252, 3818-3827. doi: 10.1016/j.apsusc.2005.05.072

18. D. Daloz, C. Rapin, P. Steinmetz and G. Michot, Corrosion Inhibition of Rapidly Solidified Mg-3\% Zn-15\% Al Magnesium Alloy with Sodium Carboxylates, Corrosion, 1998, 54, no. 6, 444-450. doi: $10.5006 / 1.3284872$

19. F. Zucchi, V. Grassi and F. Zanotto, Sodium carboxylates as inhibitors of AZ31 alloy corrosion in a synthetic cooling water, Mater. Corros., 2009, 60, 199-205. doi: $\underline{10.1002 / \mathrm{maco} .200805045}$

20. N. Dinodi, and A.N. Shetty, Alkyl carboxylates as efficient and green inhibitors of magnesium alloy ZE41corrosion in aqueous salt solution, Corros. Sci., 2014, 85, 411427. doi: $10.1016 /$ j.corsci.2014.04.052

21. Yu.I. Kuznetsov, A.M. Semiletov and A.A. Chirkunov, Inhibition of magnesium corrosion by triazoles, Int. J. Corros. Scale Inhib., 2016, 5, no. 1, 31-49. doi: 10.17675/2305-6894-2016-5-1-3

22. N.P. Andreeva, Yu.I. Kuznetsov, A.M. Semiletov and A.A. Chirkunov, Formation of passive films on magnesium in alkaline solutions and adsorption of organic acid anions on them, Korroz.: Mater., Zashch. (Corrosion: Materials, Protection), 2017, no. 2, 4148 (in Russian). 
23. V.A. Ogorodnikova, Yu.I. Kuznetsov, N.P. Andreeva and A.A. Chirkunov, Adsorbtsiya oleata natriya iz shchelochnykh rastvorov na okislennom magnii (Adsorption of sodium oleate from alkaline solutions on oxidized magnesium) Korroz.: Mater., Zashch. (Corrosion: Materials, Protection), 2018, no. 5, 27-31 (in Russian).

24. V.A. Ogorodnikova, Yu.I. Kuznetsov, A.A. Chirkunov and A.M. Semiletov, Inhibition of anodic dissolution of $\mathrm{Mg} 90$ alloy by adsorption layers of higher carboxylic acids, Int. J. Corros. Scale Inhib., 2018, 7, no. 2, 260-270. doi: 10.17675/2305-6894-2018-7-2-11

25. V.A. Ogorodnikova, Yu.I. Kuznetsov, A.Yu. Luchkin, N.P. Andreeva and A.A. Chirkunov, Adsorption of Anions of Higher Carboxylic Acids on Magnesium from Weakly Alkaline Aqueous Solutions, Russ. J. Phys. Chem. A, 2020, 94, no. 6, 11041110. doi: 10.1134/S0036024420060187

26. V.A. Ogorodnikova, Yu.I. Kuznetsov and A.A. Chirkunov, Inhibition of corrosion of Mg90 alloy by compositions based on sodium oleate. Part I. Salts of higher alkenyl and aryl carboxylates, Korroz.: Mater., Zashch. (Corrosion: Materials, Protection), 2020, no. 7, 25-32 (in Russian). doi: 10.31044/1813-7016-2020-0-7-25-32

27. V.A. Ogorodnikova, Yu.I. Kuznetsov and A.A. Chirkunov, Inhibition of corrosion of Mg90 alloy by compositions based on sodium oleate. Part II. Chelating agents and trialkoxysilanes, Korroz.: Mater., Zashch. (Corrosion: Materials, Protection), 2020, no. 9, 18-24 (in Russian). doi: 10.31044/1813-7016-2020-0-9-11-17

28. S. Szillies, P. Thissen, D. Tabatabai, F. Feil, W. Fürbeth, N. Fink and G. Grundmeier, Formation and stability of organic acid monolayers on magnesiumalloy AZ31: The role of alkyl chain length and head group chemistry, Appl. Surf. Sci., 2013, 283, 339-347. doi: $10.1016 /$ j.apsusc. 2013.06 .113

29. Yu.I. Kuznetsov and L.P. Kazansky, Physicochemical aspects of metal protection by azoles, Russ. Chem. Rev., 2008, 77, no. 3, 219-232. doi: 10.1070/RC2008v077n03ABEH003753

30. M. Finšgar and I. Milošev, Inhibition of copper corrosion by 1,2,3-benzotriazole: A review, Corros. Sci., 2010, 52, 2737-2749. doi: 10.1016/j.corsci.2010.05.002

31. A.A. Khadom, Protection of Steel Corrosion Reaction by Benzotriazoles: A Historical Background, J. Failure Anal. Prev., 2015, 15, 794-802. doi: 10.1007/s11668-015-0043$\underline{4}$

32. M.B. Petrović Mihajlović and M.M. Antonijević, Copper Corrosion Inhibitors. Period 2008-2014. A Review, Int. J. Electrochem. Sci., 2015, 10, 1027-1053.

33. Yu.I. Kuznetsov, Triazoles as a class of multifunctional corrosion inhibitors. A review. Part I. 1,2,3-Benzotriazole and its derivatives. Copper, zinc and their alloys, Int. J. Corros. Scale Inhib., 2018, 7, no. 3, 271-307. doi: 10.17675/2305-6894-2018-7-3-1

34. Yu.I. Kuznetsov, Triazoles as a class of multifunctional corrosion inhibitors. A review. Part II. 1,2,3-Benzotriazole and its derivatives. Iron and steels, Int. J. Corros. Scale Inhib., 2020, 9, no. 3, 780-811. doi: 10.17675/2305-6894-2020-9-3-1 
35. Yu.I. Kuznetsov, Triazoles as a class of multifunctional corrosion inhibitors. A review. Part III. 1,2,3-Benzotriazole and its derivatives. Aluminum alloys, Int. J. Corros. Scale Inhib., 2020, 9, no. 4, 1142-1168. doi: 10.17675/2305-6894-2020-9-4-1

36. X. Guo, M. An, P. Yang, H. Li and C. Su, Effects of benzotriazole on anodized film formed on AZ31B magnesium alloy in environmental-friendly electrolyte, J. Alloys Compd., 2009, 482, 487-497. doi: 10.1016/j.jallcom.2009.04.053

37. T.N. Ostanina, V.M. Rudoi, A.N. Ovsyannikova and V.B. Malkov, Magnesium alloys spontaneous dissolution features under external anodic polarization in presence of inhibitors, Russ. J. Electrochem., 2010, 46, 707-713. doi: 10.1134/S1023193510060169

38. J.-Y. Chen, X.-B. Chen, J.-L. Li, B. Tang, N. Birbilis and X. Wang, Electrosprayed PLGA smart containers for active anti-corrosion coating on magnesium alloy Amlite, $J$. Mater. Chem. A, 2014, 2, no. 16, 5738-5743. doi: 10.1039/c3ta14999d

39. M. Sun, A. Yerokhin, M.Ya. Bychkova, D.V. Shtansky, E.A. Levashov and A. Matthews, Self-healing plasma electrolytic oxidation coatings doped with benzotriazole loaded halloysite nanotubes on AM50 magnesium alloy, Corros. Sci., 2016, 111, 753-769. doi: $10.1016 /$ j.corsci.2016.06.016

40. J.-L. Wang, C. Ke, K. Pohl, N. Birbilis and X.-B. Chen, The unexpected role of benzotriazole in mitigating magnesium alloy corrosion: a nucleating agent for crystalline nanostructured magnesium hydroxide film, J. Electrochem. Soc., 2015, 162, C403C411. doi: 10.1149/2.0781508jes

41. O.V. Karavai, A.C. Bastos, M.L. Zheludkevich, M.G. Taryba, S.V. Lamaka and M.G.S. Ferreira, Localized electrochemical study of corrosion inhibition in microdefects on coated AZ31 magnesium alloy, Electrochim. Acta, 2010, 55, 5401-5406. doi: 10.1016/j.electacta.2010.04.064

42. D.K. Ivanou, K.A. Yasakau, S. Kallip, A.D. Lisenkov, M. Starykevich, S.V. Lamaka, M.G.S. Ferreira and M.L. Zheludkevich, Active corrosion protection coating for ZE41 magnesium alloy created by combining PEO and sol-gel techniques, RSC Adv., 2016, 6, 12553-12560. doi: 10.1039/C5RA22639B

43. Yu.I. Kuznetsov, A.M. Semiletov and A.A. Chirkunov, Inhibition of magnesium corrosion by triazoles, Int. J. Corros. Scale Inhib., 2016, 5, no. 1, 31-49. doi: 10.17675/2305-6894-2016-5-1-3

44. Ya.G. Avdeev and Yu.I. Kuznetsov, Physicochemical aspects of inhibition of acid corrosion of metals by unsaturated organic compounds, Russ. Chem. Rev., 2012, 81, no. 12, 1133-1145. doi: 10.1070/RC2012v081n12ABEH004292

45. Ya.G. Avdeev, M.V. Tyurina and Yu.I. Kuznetsov, Protection of low-carbon steel in phosphoric acid solutions by mixtures of a substituted triazole with sulfur-containing compounds, Int. J. Corros. Scale Inhib., 2014, 3, no. 4, 246-253. doi: 10.17675/23056894-2014-3-4-246-253

46. Yu.I. Kuznetsov, Organic Inhibitors of Corrosion of Metals, 1996, New York, Plenum Press, 283. 
47. A.M. Semiletov, A.A. Chirkunov, Yu.I. Kuznetsov and L.P. Kazansky, Protivokorrozionnaya zashchita magniya 5-khlorbenzotriazolom i kompozitsiyami na yego osnove (Corrosion protection of magnesium with 5-chlorobenzotriazole and compositions based on it), Korroz.: Mater., Zashch. (Corrosion: Materials, Protection), 2015, no. 11, 26-35 (in Russian).

48. S. Peljhan and A. Kokalj, DFT study of gas-phase adsorption of benzotriazole on $\mathrm{Cu}(111), \mathrm{Cu}(100), \mathrm{Cu}(110)$, and low coordinated defects thereon, Phys. Chem. Chem. Phys., 2011, 13, 20408-20417. doi: 10.1039/C1CP21873E

49. S.V. Lamaka, B. Vaghefinazari, Di Mei, R.P. Petrauskas, D. Höche and M.L. Zheludkevich, Comprehensive screening of Mg corrosion inhibitors, Corros. Sci., 2017, 128, 224-240. doi: 10.1016/j.corsci.2017.07.011

50. A.Yu. Luchkin, O.A. Goncharova, N.N. Andreev, I.A. Arkhipushkin, L.P. Kazansky and Yu.I. Kuznetsov, 5-chloro-1,2,3-benzotriazol kak kamernyi ingibitor korrozii magnievogo splava MA8, Korroz.: Mater., Zashch. (Corrosion: Materials, Protection), 2020, no. 4, $27-35$ (in Russian). doi: 10.31044/1813-7016-2020-0-4-27-35 